\title{
Role of diclofenac in the prevention of postpericardiotomy syndrome after cardiac
}

\section{surgery}

\author{
Utkan Sevuk' \\ Erkan Baysal' \\ Rojhat Altindag ${ }^{2}$ \\ Baris Yaylak ${ }^{2}$ \\ Mehmet Sahin Adiyaman ${ }^{2}$ \\ Nurettin $\mathrm{Ay}^{3}$ \\ Vahhac Alp ${ }^{3}$ \\ Unal Beyazit ${ }^{3}$ \\ 'Department of Cardiovascular \\ Surgery, ${ }^{2}$ Department of Cardiology, \\ ${ }^{3}$ Department of General Surgery, \\ Diyarbakir Gazi Yasargil Education and \\ Research Hospital, Diyarbakir, Turkey
}

This article was published in the following Dove Press journal:

Vascular Health and Risk Management

30 June 2015

Number of times this article has been viewed

\begin{abstract}
Objective: Postpericardiotomy syndrome (PPS), which is thought to be related to autoimmune phenomena, represents a common postoperative complication in cardiac surgery. Late pericardial effusions after cardiac surgery are usually related to PPS and can progress to cardiac tamponade. Preventive measures can reduce postoperative morbidity and mortality related to PPS. In a previous study, diclofenac was suggested to ameliorate autoimmune diseases. The aim of this study was to determine whether postoperative use of diclofenac is effective in preventing early PPS after cardiac surgery.
\end{abstract}

Methods: A total of 100 patients who were administered oral diclofenac for postoperative analgesia after cardiac surgery and until hospital discharge were included in this retrospective study. As well, 100 patients undergoing cardiac surgery who were not administered nonsteroidal anti-inflammatory drugs were included as the control group. The existence and severity of pericardial effusion were determined by echocardiography. The existence and severity of pleural effusion were determined by chest X-ray.

Results: PPS incidence was significantly lower in patients who received diclofenac $(20 \% \mathrm{vs}$ $43 \%)(P<0.001)$. Patients given diclofenac had a significantly lower incidence of pericardial effusion $(15 \%$ vs $30 \%)(P=0.01)$. Although not statistically significant, pericardial and pleural effusion was more severe in the control group than in the diclofenac group. The mean duration of diclofenac treatment was $5.11 \pm 0.47$ days in patients with PPS and $5.27 \pm 0.61$ days in patients who did not have PPS $(P=0.07)$. Logistic regression analysis demonstrated that diclofenac administration (odds ratio [OR] $0.34,95 \%$ confidence interval [CI] $0.18-0.65, P=0.001$ ) was independently associated with PPS occurrence.

Conclusion: Postoperative administration of diclofenac may have a protective role against the development of PPS after cardiac surgery.

Keywords: pericardial effusion, pleural effusion, cardiac tamponade

\section{Introduction}

Postpericardiotomy syndrome (PPS) represents a common postoperative complication in cardiac surgery and remains an important cause of morbidity after cardiac surgery. PPS incidence after cardiac surgery has been reported as $10 \%-40 \% .{ }^{1-4}$ In the first week after the surgery, pericardial effusions are considered to result from surgical bleeding. Pericardial effusions occurring more than 7 days after surgery are usually related to PPS and can progress to cardiac tamponade. ${ }^{2}$ Prevalence of late pericardial tamponade after cardiac surgery varies in different studies, from $0.8 \%$ to $8.5 \%$, and may be life threatening. ${ }^{5-7}$ Preventive measures can reduce postoperative morbidity and mortality related to PPS, decrease management costs, and improve quality of life.
Correspondence: Utkan Sevuk Diyarbakir Gazi Yașargil Egitim ve Arastirma Hastanesi, Kalp ve Damar Cerrahisi Klinigi, 3 kat, Uckuyular Diyarbakir, 21010 , Turkey Tel +90505 5307095

Email utkansevuk@gmail.com 
PPS is thought to be related to inflammation and autoimmune phenomena. ${ }^{8-10}$ Cardiac surgery with cardiopulmonary bypass (CPB) is also associated with the development of a systemic inflammatory response and may enhance the development of PPS. ${ }^{11}$ Only a few studies on pharmaceutical prophylaxis to reduce the incidence of PPS have been performed thus far. ${ }^{2,4,12-15}$

Nonsteroidal anti-inflammatory drugs (NSAIDs) are widely used for the management of postoperative pericardial effusions. NSAIDs were shown to be efficacious in the treatment of postoperative pericardial effusion. ${ }^{16}$ However, whether NSAIDs reduces the incidence of PPS after cardiac surgery is still a controversial issue. Diclofenac (2-(2,6-dichloranilino) phenylacetic acid) is an NSAID that produces analgesic, antipyretic, and anti-inflammatory effects and is widely used for the treatment of moderate pain and inflammation.

The aim of this study was to determine whether postoperative use of diclofenac sodium is effective in preventing early PPS after cardiac surgery with CPB. As far as we know, this was the first study to evaluate the efficacy of diclofenac in prevention of PPS after cardiac surgery.

\section{Materials and methods Study population}

The present study was approved by the Diyarbakir Gazi Yasargil Education and Research Hospital ethics committee and complies with the requirements of the Declaration of Helsinki. We retrospectively reviewed the medical records of patients who underwent elective first-time cardiac surgery with CPB between January 2011 and June 2014. A total 100 patients who were administered $50 \mathrm{mg}$ oral diclofenac sodium (Dikloron $50 \mathrm{mg}$; Deva İlaç, İstanbul, Turkey) every 8 hours starting the first day after surgery and continuing until hospital discharge were included in this study. A further 100 patients undergoing cardiac surgery who were not administered NSAIDs in the postoperative period were included as the control group.

The exclusion criteria were gastroduodenal ulcer; previous history of gastrointestinal hemorrhage; renal failure; hepatic failure; hematologic disorders; rheumatic heart disease; emergency procedures; poor ventricle function; coronary artery disease; no postoperative echocardiography available; postoperative effusion in the first week after the surgery; corticosteroids in the perioperative period; international normalized ratio (INR) values above the therapeutic range; and contraindications to diclofenac.

The primary end point was the occurrence of PPS and cardiac tamponade. The diagnosis of PPS was established when the patient met two of the five following criteria: unexplained postoperative fever lasting beyond the first postoperative week, pleuritic chest pain, pericardial or pleural friction rub, new pleural effusion, and new pericardial effusion after surgery. ${ }^{2}$

\section{Data collection}

Demographic, clinical, and laboratory parameters were collected from patients' medical records. All chest X-rays and echocardiograms were reassessed. Patients' temperature was obtained from patients' charts.

Transthoracic echocardiography and chest X-ray were performed before discharge and on postoperative day $15 \pm 1$ in all patients, as a part of a standard protocol for postoperative management. The existence and severity of pericardial effusion were determined by echocardiography. In our hospital, pericardial effusion is evaluated in all available echo windows and measured during the diastolic cardiac phase. The size of the pericardial effusion was graded as: mild (echo-free space in diastole $<10 \mathrm{~mm}$ ), moderate $(10-20 \mathrm{~mm})$, or large $(>20 \mathrm{~mm}$ ). Cardiac tamponade was defined as a hemodynamically significant cardiac compression caused by pericardial fluid. Late pericardial tamponade was defined as a pericardial effusion occurring after 7 days postoperative. The existence and severity of pleural effusion were determined by chest X-ray. The size of the pleural effusion was graded as: below level of the diaphragm; $<25 \%$ of the thorax; $>25 \%$ of the thorax.

The use of oral diclofenac for postoperative analgesia is a standard of practice in our clinic except in patients with ischemic heart disease. In patients with ischemic heart disease or contraindications to diclofenac, paracetamol was given for postoperative analgesia. After discharge, oral paracetamol was provided for analgesia. In all patients, aspirin was discontinued 1 week before surgery and was resumed within 6-12 hours after surgery. All patients received a gastroprotective agent (lansoprazole) in the perioperative period.

\section{Statistical analysis}

Statistical analysis was conducted using SPSS for Windows version 17 (SPSS Inc. Chicago, IL, USA). All variables were investigated using visual (histograms, probability plots) and analytic methods (Kolmogorov-Smirnov test) to determine whether or not they were normally distributed. Continuous variables were reported as means and standard deviation for normally distributed variables and as medians and interquartile range (IQR) for the non-normally distributed variables. Categorical variables were presented using numbers and percentages. 
Patients were divided into two subgroups according to whether they received diclofenac or not. Comparison between two groups was performed using the $\chi^{2}$ and fisher exact test for qualitative variables, independent $t$-test for normally distributed continuous variables, and the Mann-Whitney $U$-test for non-normally distributed continuous variables. Patients were further categorized into two subgroups according to the presence or absence of PPS. A similar analysis to that earlier was made for PPS groups. Logistic regression analysis was used to evaluate the associations between PPS and diclofenac administration. $P$-values $<0.05$ were considered statistically significant.

\section{Results \\ Study population}

A total of 200 patients were included in the study. Clinical characteristics of the patients who received diclofenac $(n=100 ; 62$ males; mean age 52.09 \pm 8.4 years) and the patients who were not given NSAIDs ( $\mathrm{n}=100 ; 51$ males; mean age $52.1 \pm 7.9$ years) are presented in Table 1 . There were no

Table I Clinical characteristics of the patients

\begin{tabular}{|c|c|c|c|}
\hline & $\begin{array}{l}\text { Diclofenac } \\
\text { group }(n=100)\end{array}$ & $\begin{array}{l}\text { Control group } \\
(n=100)\end{array}$ & $P$-value \\
\hline Age, years & $52.09 \pm 8.4$ & $52.1 \pm 7.9$ & 0.96 \\
\hline Male & 62 & 51 & 0.11 \\
\hline $\mathrm{HT}$ & 57 & 55 & 0.89 \\
\hline DM & 34 & 30 & 0.64 \\
\hline \multicolumn{4}{|l|}{ Smoking } \\
\hline COPD & 20 & 27 & 0.31 \\
\hline \multicolumn{4}{|l|}{ Operation } \\
\hline Atrial septal defect & 6 & 4 & 0.74 \\
\hline Ascending aorta & 18 & 23 & 0.48 \\
\hline \multicolumn{4}{|l|}{ replacement } \\
\hline MVR & 40 & 37 & 0.77 \\
\hline AVR & 28 & 32 & 0.64 \\
\hline AVR+MVR & 8 & 4 & 0.37 \\
\hline CPB time, min & $104.7 \pm 29.6$ & $101.2 \pm 27.9$ & 0.38 \\
\hline X-clamp time, $\min$ & $68 \pm 22.8$ & $65.6 \pm 20.3$ & 0.41 \\
\hline \multicolumn{4}{|l|}{ Medications } \\
\hline Warfarin & 79 & 78 & 0.86 \\
\hline ACE inhibitor/ & 60 & 63 & 0.66 \\
\hline \multicolumn{4}{|l|}{ ARB } \\
\hline Amiodarone & 18 & II & 0.16 \\
\hline Diuretic & 66 & 64 & 0.76 \\
\hline$\beta$-blocker & 81 & 85 & 0.45 \\
\hline Statin & 10 & 15 & 0.28 \\
\hline Ca channel blocker & 13 & 17 & 0.42 \\
\hline \multicolumn{4}{|l|}{ Side effects } \\
\hline GI bleeding & 0 & 0 & \\
\hline
\end{tabular}

Note: Values were expressed as $\mathrm{n}$ or as mean \pm SD.

Abbreviations: ACE inhibitor, angiotensin converting enzyme inhibitor; ARB, angiotensin receptor blocker; AVR, aortic valve replacement; COPD, chronic obstructive pulmonary disease; CPB, cardiopulmonary bypass; DM, diabetes mellitus; $\mathrm{Gl}$, gastrointestinal; HT, hypertension; MVR, mitral valve replacement; SD, standard deviation; min, minutes. statistically significant differences in demographic and clinical characteristics between the two groups. No gastrointestinal bleeding was observed in patients who received diclofenac.

\section{Effects of diclofenac administration on PPS occurrence}

PPS incidence was significantly lower in patients who received diclofenac than in those who were not given diclofenac $(P<0.001)$. Patients given diclofenac had a significantly lower incidence of pericardial effusion $(P=0.01)$. There was no significant difference in the severity of pericardial and pleural effusion between the two groups. Although not statistically significant, pericardial and pleural effusion was more severe in the control group than in the diclofenac group. The efficacy of diclofenac for the primary prevention of PPS is presented in Table 2.

Patients were further categorized into two subgroups according to the presence ( $n=63 ; 30$ males; mean age $50.9 \pm 9.4$ years) or absence ( $\mathrm{n}=137 ; 83$ males; mean age $52.6 \pm 7.4$ years) of PPS (Table 3). The mean duration of diclofenac treatment was 5.11 \pm 0.47 days in patients with PPS and 5.27 \pm 0.61 days in patients who did not have PPS ( $P=0.07)$. Table 3 shows the comparison of clinical characteristics in patients with or without PPS. There were no statistically significant differences in clinical characteristics between the two groups.

\section{Multivariate analysis}

Logistic regression analysis demonstrated that diclofenac administration (odds ratio [OR] 0.34, 95\% confidence interval $[\mathrm{CI}] 0.18-0.65, P=0.001)$ was independently associated

Table 2 Efficacy of diclofenac for the prevention of postpericardiotomy syndrome

\begin{tabular}{|c|c|c|c|}
\hline & $\begin{array}{l}\text { Diclofenac } \\
\text { group }(n=\mid 00)\end{array}$ & $\begin{array}{l}\text { Control } \\
\text { group }(n=\mid 00)\end{array}$ & $P$-value \\
\hline PPS & 20 & 43 & $<0.001$ \\
\hline $\begin{array}{l}\text { Postoperative pericardial } \\
\text { effusion }\end{array}$ & 15 & 30 & 0.01 \\
\hline Mild, $<10 \mathrm{~mm}$ & 12 & 19 & 0.1 \\
\hline Moderate, $10-20 \mathrm{~mm}$ & 3 & 7 & 0.44 \\
\hline Large, $>20 \mathrm{~mm}$ & I & 3 & 0.49 \\
\hline Cardiac tamponade & 0 & 4 & 0.12 \\
\hline Pleural effusion & 8 & 16 & 0.08 \\
\hline $\begin{array}{l}\text { Below level of } \\
\text { diaphragm }\end{array}$ & 6 & 13 & \\
\hline$<25 \%$ of the thorax & I & 2 & \\
\hline$>25 \%$ of the thorax & I & I & \\
\hline
\end{tabular}

Note: Values are expressed as $\mathrm{n}$.

Abbreviation: PPS, postpericardiotomy syndrome. 
Table 3 Comparison of clinical characteristics in patients with or without postpericardiotomy syndrome

\begin{tabular}{|c|c|c|c|}
\hline & \multicolumn{2}{|c|}{$\begin{array}{l}\text { Postpericardiotomy } \\
\text { syndrome }\end{array}$} & \multirow[t]{2}{*}{$P$-value } \\
\hline & $\begin{array}{l}\text { Yes } \\
(n=63)\end{array}$ & $\begin{array}{l}\text { No } \\
(n=137)\end{array}$ & \\
\hline Age, years & $50.9 \pm 9.4$ & $52.6 \pm 7.4$ & 0.16 \\
\hline Male & $30(47.6)$ & $83(60.6)$ & 0.09 \\
\hline $\mathrm{HT}$ & $31(49.2)$ & $81(59.1)$ & 0.19 \\
\hline DM & $19(30.2)$ & $45(32.8)$ & 0.7 \\
\hline Smoking & 27 (42.9) & $51(37.2)$ & 0.45 \\
\hline COPD & $15(23.8)$ & $32(23.4)$ & 0.94 \\
\hline \multicolumn{4}{|l|}{ Operation } \\
\hline Atrial septal defect & $5(7.9)$ & $5(3.6)$ & 0.2 \\
\hline $\begin{array}{l}\text { Ascending aorta } \\
\text { replacement }\end{array}$ & $17(27)$ & $24(17.5)$ & 0.12 \\
\hline MVR & $26(4 \mid .3)$ & $5 I(37.2)$ & 0.58 \\
\hline AVR & $12(19)$ & $48(35)$ & 0.02 \\
\hline AVR+MVR & $3(4.8)$ & $9(6.6)$ & 0.61 \\
\hline CPB time, $\min$ & $98.4 \pm 30.8$ & $105.02 \pm 27.6$ & 0.13 \\
\hline $\mathrm{X}$-clamp time, $\min$ & $62.8 \pm 20.9$ & $68.6 \pm 21.6$ & 0.07 \\
\hline $\begin{array}{l}\text { Duration of } \\
\text { diclofenac treatment, } \\
\text { days }\end{array}$ & $5.11 \pm 0.47$ & $5.27 \pm 0.61$ & 0.07 \\
\hline \multicolumn{4}{|l|}{ Medication use } \\
\hline Warfarin & $46(73)$ & III (8I) & 0.2 \\
\hline $\begin{array}{l}\text { ACE inhibitor/ } \\
\text { ARB }\end{array}$ & $42(66.7)$ & 81 (59.1) & 0.3 \\
\hline Amiodarone & $10(15.9)$ & $19(13.9)$ & 0.7 \\
\hline Diuretic & $92(67.2)$ & $38(60.3)$ & 0.34 \\
\hline$\beta$-blocker & $55(87.3)$ & $1 \mathrm{II}(8 \mathrm{I})$ & 0.27 \\
\hline Statin & $9(14.3)$ & $16(11.7)$ & 0.6 \\
\hline $\begin{array}{l}\text { Ca channel } \\
\text { blocker }\end{array}$ & II (I7.5) & $19(13.9)$ & 0.5 \\
\hline
\end{tabular}

Note: Values were expressed as $\mathrm{n}(\%)$ or as mean \pm SD.

Abbreviations: ACE inhibitor, angiotensin-converting enzyme inhibitor; ARB, angiotensin receptor blocker; AVR, aortic valve replacement; COPD, chronic obstructive pulmonary disease; $\mathrm{CPB}$, cardiopulmonary bypass; DM, diabetes mellitus; $\mathrm{HT}$, hypertension; MVR, mitral valve replacement; SD, standard deviation; min, minutes.

with PPS occurrence after correction for age, male sex, $\mathrm{X}$-clamp time, and CPB time. The results of the logistic regression analysis are presented in Table 4.

\section{Discussion}

Diclofenac administration was found to be protective against PPS in patients undergoing cardiac surgery. Patients given

Table 4 Results of the logistic regression analysis

\begin{tabular}{llll}
\hline & OR & 95\% Cl & P-value \\
\hline Age & 0.97 & $0.93-1.01$ & 0.15 \\
Male sex & 1.58 & $0.84-2.99$ & 0.15 \\
CPB time & 0.99 & $0.97-1.02$ & 0.8 \\
X-clamp time & 0.99 & $0.96-1.01$ & 0.51 \\
Diclofenac administration & 0.34 & $0.18-0.65$ & 0.001 \\
\hline
\end{tabular}

Abbreviations: $\mathrm{Cl}$, confidence interval; $\mathrm{CPB}$, cardiopulmonary bypass; OR, odds ratio. diclofenac had a lower incidence of pericardial effusion. Although not statistically significant, pericardial and pleural effusion was more severe in the patients who did not receive diclofenac.

PPS is considered as an immune-mediated inflammatory process triggered by cardiac antigen exposure. ${ }^{8-10,17,18}$ Myocardial muscle injury during operation leads to release of autoantigens. The release of these autoantigens can trigger host immune responses, with subsequent production of anti-heart antibodies and immune complexes. Engle et al showed the presence of anti-heart antibody at high titers in PPS patients. ${ }^{17}$ De Scheerder et al found a significant correlation between the development of PPS and increased immune complexes. The researchers also demonstrated a significant correlation between postoperative anti-heart antibodies and increased immune complexes, suggesting a possible pathogenic role. ${ }^{19}$ Maisch et al further examined the subtypes of specific autoantibodies and showed that $95 \%$ of their patients with PPS had antibodies to myocardium and skeletal muscle. Surgery and trauma were hypothesized etiologies for the myocardial injury that caused the release of these myocardial antigens. ${ }^{20}$ Furthermore, cardiac surgery with CPB initiates a systemic inflammatory response and this may enhance the development of PPS. ${ }^{11}$

Diclofenac is a nonselective NSAID that is widely used for pain management and for the treatment of inflammation. It is known that diclofenac inhibits both cyclooxygenase (COX)-1 and COX-2 and suppresses prostaglandin synthesis in the injured tissues and the central nervous system. Diclofenac is readily absorbed after oral administration, and about half the active substance is metabolized during its first passage through the liver. Diclofenac is extensively bound to $(\geq 99.5 \%)$ serum albumin. It is metabolized in the liver, and the mean terminal drug half-life in plasma is between 1 hour and 2 hours after oral doses. Several possible mechanisms explain how diclofenac may reduce the PPS incidence. Diclofenac inhibits the activity of COX, which catalyses conversion of arachidonic acid to inflammatory mediators, including prostaglandins, thromboxanes, and prostacyclins. Moreover, diclofenac is reported to inhibit phospholipase A2 and the synthesis of leukotrienes..$^{21}$ Diclofenac also impairs migration and accumulation of leukocytes and diminishes NO production by macrophages. ${ }^{22-26} \mathrm{Kv} 1.3$ voltage-dependent potassium channels play a crucial role in the activation and proliferation of T-lymphocytes and macrophages. Patients with autoimmune diseases show a high number of effector memory T-cells, which are characterized by a high expression of Kv1.3, and Kv1.3 inhibitors were shown to ameliorate 
autoimmune disorders in vivo. ${ }^{27} \mathrm{~A}$ previous study found that diclofenac inhibits the expression of Kv1.3 voltagedependent potassium channels in macrophages and $\mathrm{T}$ lymphocytes, which was accompanied by impaired inflammatory response in these cells. It was concluded that diclofenac administration could provide additional benefits in therapies against autoimmune diseases associated with inflammation. Finally, inhibition of the Kv1.3 voltage-dependent potassium channels in macrophages and $\mathrm{T}$ lymphocytes may be another mechanism accounting for the efficacy of diclofenac in reducing the incidence of PPS after cardiac surgery. ${ }^{28}$

Previous study examined the efficacy of NSAIDs in the treatment of PPS. In a double-blind, placebo-controlled, randomized study in 149 adults, Horneffer et al examined the safety and efficacy of ibuprofen and indomethacin for the treatment of PPS after cardiac surgery. ${ }^{16}$ Patients received a 10-day course of ibuprofen or indomethacin. Ibuprofen and indomethacin were $90.2 \%$ and $88.7 \%$ effective, respectively, and both were significantly more effective than placebo. On the other hand, Meurin et al conducted a double-blind, randomized trial to assess whether diclofenac was effective in reducing postoperative pericardial effusion volume. ${ }^{29}$ The researchers administered $50 \mathrm{mg}$ diclofenac twice daily for 14 days for postoperative effusion lasting more than 7 days. Diclofenac failed to reduce the either the size of the effusion or the progression to cardiac tamponade.

While several studies examined the efficacy of NSAIDs in the treatment of PPS, only a few studies focused on the role of NSAIDs in primary prevention of PPS. Niva et al conducted a randomized study to evaluate the efficacy of the prophylactic use of diclofenac in the prevention of pericardial effusion after coronary artery bypass surgery. ${ }^{30}$ Diclofenac sodium was administered orally every 8 hours to 22 patients after the discharge from the intensive care unit for $5.2 \pm 1.2$ days. They found that diclofenac lessened the degree of inflammatory reaction after cardiac surgery and suggested it might be useful in the prevention and in the management of early pericardial effusions after cardiac surgery. However, these differences were not statistically significant, and the authors acknowledged that their study was underpowered to detect the beneficial effects of diclofenac. Our study differs from this study in that we evaluated the protective effect of diclofenac in patients with PPS. Early pericardial effusions are probably related to pericardial bleeding and perioperative trauma and may not respond to anti-inflammatory agents. Béland et al examined the efficacy of a prophylactic regimen of acetylsalicylic acid (ASA) on the incidence of pericardial effusion in 74 children aged $0.3-21.4$ years after cardiac surgery with $\mathrm{CPB} .{ }^{31}$ Patients were randomized to receive aspirin $60 \mathrm{mg} / \mathrm{kg} /$ day for 7 days starting on the third postoperative day. The researchers showed that aspirin had no protective effect on the occurrence of pericardial effusion in this small series of patients. However, this study was also not powered to detect the potential effects of ASA on pericardial effusions, and the study group was heterogeneous with respect to age groups and etiology - the study group included both children and adults. In addition, patients were not evaluated in terms of PPS. Gill et al evaluated the effectiveness of ASA prophylaxis in preventing PPS after surgical closure of atrial septal defects in pediatric patients. ${ }^{12}$ The study group received prophylactic ASA $20-50 \mathrm{mg} / \mathrm{kg} /$ day for 1-6 weeks after surgery. The researchers showed that ASA had no protective effect on the occurrence of PPS in pediatric patients. Nevertheless, the authors acknowledged that ASA prophylaxis dose and duration were variable or poorly documented. As opposed to the results of these studies, we found a protective effect of diclofenac against PPS. This discrepancy is likely due to study design. Our study was designed to evaluate the protective effect of diclofenac in adult patients with PPS. It is known that immune response to a stimulus may differ between adults and children. ${ }^{32}$ The discrepancies could also have been caused by the use of strict exclusion criteria in our study.

This study had some limitations. First, the major limitation of our study was related to the definition of PPS, because there is no general agreement on how to diagnose the syndrome - there are no pathognomonic features of this condition. Second, this was a retrospective study. Finally, we were not able to undertake a detailed safety analysis of diclofenac, due to the retrospective design of our study.

\section{Conclusion}

Postoperative administration of diclofenac may have a protective role against the development of PPS in patients undergoing cardiac surgery. Thus, diclofenac administration may be useful to reduce postoperative morbidity and mortality related to PPS, thereby decreasing management costs and improving quality of life after cardiac surgery.

\section{Disclosure}

The authors report no conflicts of interest in this work.

\section{References}

1. Prince SE, Cunha BA. Postpericardiotomy syndrome. Heart Lung. 1997;26(2):165-168.

2. Finkelstein Y, Shemesh J, Mahlab K, et al. Colchicine for the prevention of postpericardiotomy syndrome. Herz. 2002;27(8):791-794. 
3. Weitzman LB, Tinker WP, Kronzon I, Cohen ML, Glassman E, Spencer FC. The incidence and natural history of pericardial effusion after cardiac surgery--an echocardiographic study. Circulation. 1984;69(3):506-511.

4. Imazio M, Trinchero R, Brucato A, et al; COPPS Investigators. COlchicine for the Prevention of the Post-pericardiotomy Syndrome (COPPS): a multicentre, randomized, double-blind, placebo-controlled trial. Eur Heart J. 2010;31(22):2749-2754.

5. Pepi M, Muratori M, Barbier P, et al. Pericardial effusion after cardiac surgery: incidence, site, size, and haemodynamic consequences. Br Heart J. 1994;72(4):327-331.

6. Malouf JF, Alam S, Gharzeddine W, Stefadouros MA. The role of anticoagulation in the development of pericardial effusion and late tamponade after cardiac surgery. Eur Heart J. 1993;14(11):1451-1457.

7. Sagristà-Sauleda J, MercéAS, Soler-Soler J. Diagnosis and management of pericardial effusion. World J Cardiol. 2011;3(5):135-143.

8. Erlich JF, Paz Z. Postpericardial injury syndrome: an autoimmune phenomenon. Clin Rev Allergy Immunol. 2010;38(2-3):156-158.

9. Kim S, Sahn SA. Postcardiac injury syndrome. An immunologic pleural fluid analysis. Chest. 1996;109(2):570-572.

10. Mason TG, Neal WA, DiBartolomeo AG. Elevated antinuclear antibody titers and the postpericardiotomy syndrome. $J$ Pediatr. 1990;116(3):403-404.

11. Paparella D, Yau TM, Young E. Cardiopulmonary bypass induced inflammation: pathophysiology and treatment. An update. Eur J Cardiothorac Surg. 2002;21(2);232-244.

12. Gill PJ, Forbes K, Coe JY. The effect of short-term prophylactic acetylsalicylic acid on the incidence of postpericardiotomy syndrome after surgical closure of atrial septal defects. Pediatr Cardiol. 2009;30(8):1061-1067.

13. Mott AR, Fraser CD, Kusnoor AV, et al. The effect of short-term prophylactic methylprednisolone on the incidence and severity of postpericardiotomy syndrome in children undergoing cardiac surgery with cardiopulmonary bypass. J Am Coll Cardiol. 2001;37(6): 1700-1706.

14. Wilson NJ, Webber SA, Patterson MW, Sandor GG, Tipple M, LeBlanc J. Double-blind placebo-controlled trial of corticosteroids in children with postpericardiotomy syndrome. Pediatr Cardiol. 1994;15(2):62-65.

15. Bunge JJ, van Osch D, Dieleman JM, et al; Dexamethasone for Cardiac Surgery (DECS) Study Group. Dexamethasone for the prevention of postpericardiotomy syndrome: A DExamethasone for Cardiac Surgery substudy. Am Heart J. 2014;168(1):126-131.

16. Horneffer PJ, Miller RH, Pearson TA, Rykiel MF, Reitz BA, Gardner TJ. The effective treatment of postpericardiotomy syndrome after cardiac operations. A randomized placebo-controlled trial. JThorac Cardiovasc Surg. 1990;100(2):292-296.

17. Engle MA, McCabe JC, Ebert PA, Zabriskie J. The Postpericardiotomy syndrome and antiheart antibodies. Circulation. 1974;49(3):401-406.
18. Engle MA. Humoral immunity and heart disease: postpericardiotomy syndrome. Adv Exp Med Biol. 1983;161:471-478.

19. De Scheerder I, Wulfrank D, Van Renterghem L, et al. Association of anti-heart antibodies and circulating immune complexes in the postpericardiotomy syndrome. Clin Exp Immunol. 1984;57(2):423-428.

20. Maisch B, Berg PA, Kochsiek K. Clinical significance of immunopathological findings in patients with post-pericardiotomy syndrome. I. Relevance of antibody pattern. Clin Exp Immunol. 1979; 38(2):189-197.

21. Gan TJ. Diclofenac: an update on its mechanism of action and safety profile. Curr Med Res Opin. 2010;26(7):1715-1731.

22. Perianin A, Gougerot-Pocidalo MA, Giroud JP, Hakim J. Diclofenac sodium, a negative chemokinetic factor for neutrophil locomotion. Biochem Pharmacol. 1985;34(19):3433-3438.

23. Prescott MF, McBride CK, Venturini CM, Gerhardt SC. Leukocyte stimulation of intimal lesion formation is inhibited by treatment with diclofenac sodium and dexamethasone. J Cardiovasc Pharmacol. 1989;14 Suppl 6:S76-S81.

24. Marsolais D, Côté CH, Frenette J. Nonsteroidal anti-inflammatory drug reduces neutrophil and macrophage accumulation but does not improve tendon regeneration. Lab Invest. 2003;83(7):991-999.

25. Martinez LL, Oliveira MA, Miguel AS, et al. Losartan attenuates the antimigratory effect of diclofenac in spontaneously hypertensive rats. J Cardiovasc Pharmacol. 2005;46(2):190-199.

26. Cho JY. Immunomodulatory effect of nonsteroidal anti-inflammatory drugs (NSAIDs) at the clinically available doses. Arch Pharm Res. 2007;30(1):64-74.

27. Beeton C, Wulff H, Standifer NE, et al. Kv1.3 channels are a therapeutic target for T cell-mediated autoimmune diseases. Proc Natl Acad Sci US A. 2006;103(46):17414-17419.

28. Villalonga N, David M, Bielańska J, et al. Immunomodulatory effects of diclofenac in leukocytes through the targeting of Kv1.3 voltage-dependent potassium channels. Biochem Pharmacol. 2010;80(6):858-866.

29. Meurin P, Tabet JY, Thabut G, et al; French Society of Cardiology. Nonsteroidal anti-inflammatory drug treatment for postoperative pericardial effusion: a multicenter randomized, double-blind trial. Ann Intern Med. 2010;152(3):137-143.

30. Niva M, Biancari F, Valkama J, Juvonen J, Satta J, Juvonen T. Effects of diclofenac in the prevention of pericardial effusion after coronary artery bypass surgery. A prospective, randomized study. $J$ Cardiovasc Surg (Torino). 2002;43(4):449-453.

31. Béland MJ, Paquet M, Gibbons JE, Tchervenkov CI, Dobell AR. Pericardial effusion after cardiac surgery in children and effects of aspirin for prevention. Am J Cardiol. 1990;65(18):1238-1241.

32. Miller RH, Horneffer PJ, Gardner TJ, Rykiel MF, Pearson TA. The epidemiology of the postpericardiotomy syndrome: a common complication of cardiac surgery. Am Heart J. 1988;116(5 Pt 1): 1323-1329.
Vascular Health and Risk Management

\section{Publish your work in this journal}

Vascular Health and Risk Management is an international, peerreviewed journal of therapeutics and risk management, focusing on concise rapid reporting of clinical studies on the processes involved in the maintenance of vascular health; the monitoring, prevention and treatment of vascular disease and its sequelae; and the involvement of
Dovepress

metabolic disorders, particularly diabetes. This journal is indexed on PubMed Central and MedLine. The manuscript management system is completely online and includes a very quick and fair peer-review system, which is all easy to use. Visit http://www.dovepress.com/ testimonials.php to read real quotes from published authors. 